\title{
Дендрохронологический анализ
}

\section{исторического объекта}

горно-добывающего производства на Алтае

\author{
Н.И. Быков*, Н.В. Малышева \\ Алтайский государственный университет, \\ Россия 656049, г. Барнаул, пр. Ленина, $61^{1}$
}

Received 2.03.2012, received in revised form 9.03.2012, accepted 17.03.2012

B статье представлень результаты дендрохронологического изучения и датирования исторического объекта горно-добывающего производства, обнаруженного в предгорьях Алтая в 2010-2011 га. при проведении вскрышных работ на Мурзинском карьере. Сооружение представляетсобойкрепьстволавертикальнойгорнойвыработки, существовавиейздесьранее. В ходе комплексного анализа было установлено, что для строительства объекта использовали стволь лиственницы, содержащцие 35-102 годичных колец и произраставиие на высоте 600800 м. Наиболее вероятным годом заготовки древесины для исследуемого сооружения на основе двухступенчатого датирования с последующей верификацией результатов является 1772 г. Полученные выводы позволили уточнить особенности и хронологию хозяйственного освоения данной территории.

Ключевые слова: дендрохронология, дендроархеология, горно-рудное производство.

\section{Введение}

История горно-рудного дела на юге Западной Сибири, которое послужило стимулом для освоения территории Алтайского края, начинается в XVIII в. и первоначально связана с именем Акинфия Демидова. Алтай был крупным центром по добыче меди, серебра, а также золота в царской России. Однако крупных памятников горно-добывающего производства на Алтае не было найдено. В связи с этим большой резонанс приобрело обнаруженное в 2010-2011 гг. в предгорьях Алтая деревянное сооружение. Было высказано предположение о том, что время сооружения ископаемого объекта может относиться к периоду первого освоения данного месторождения (XVIII в.) и, следовательно, объект является историческим памятником. На первом этапе изучения была поставлена цель - провести комплексный анализ древесного мате-

* Corresponding author E-mail address: nikolai_bykov@mail.ru

(C) Siberian Federal University. All rights reserved 
риала и временну́ю идентификацию объекта, на втором - уточняющее датирование. Методическую основу исследования составляет дендрохронологический метод, который широко используется для определения возраста археологических объектов и деревянных строений (Черных, 1996).

\section{Материалы и методы}

Исторический объект был обнаружен в ходе вскрышных работ в карьере действующего Мурзинского - I месторождения, в районе с. Акимовка Краснощековского района Алтайского края (рис. 1). Обнаруженное деревянное сооружение имеет форму сруба. Положение объекта и его конструкционные особенности свидетельствуют о том, что оно являлось крепью ствола вертикальной горной выработки, существовавшей здесь ранее. На момент отбора образцов для дендрохронологического анализа на поверхности находились 22 венца. Высота открытой части соо- ружения составила 4 м (общая высота более 50 м), ширина - около 2 м. В целом, на данном участке обнаружен горно-добывающий комплекс: шахта, штольня, карьер. В связи с этим возникла необходимость датирования сооружения. Особенностью выполняемой работы была ее срочность, так как это влияло на график работы горно-добывающего предприятия.

Дендрохронологическое изучение деревянного объекта было выполнено в два этапа: предварительное датирование и уточняющее.

На первом этапе, в ходе полевого исследования объекта «Мурзинский сруб», было отобрано 10 буровых кернов и 10 поперечных спилов. Керны были взяты с помощью возрастного бурава. Они были отобраны со 2-го по 20-й венец с разных сторон сруба и имели диаметр 4 мм. Спилы толщиной примерно 5 см были получены с торцевой части бревен преимущественно в нижней части сруба, и лишь два образца были взяты с верхних вен-

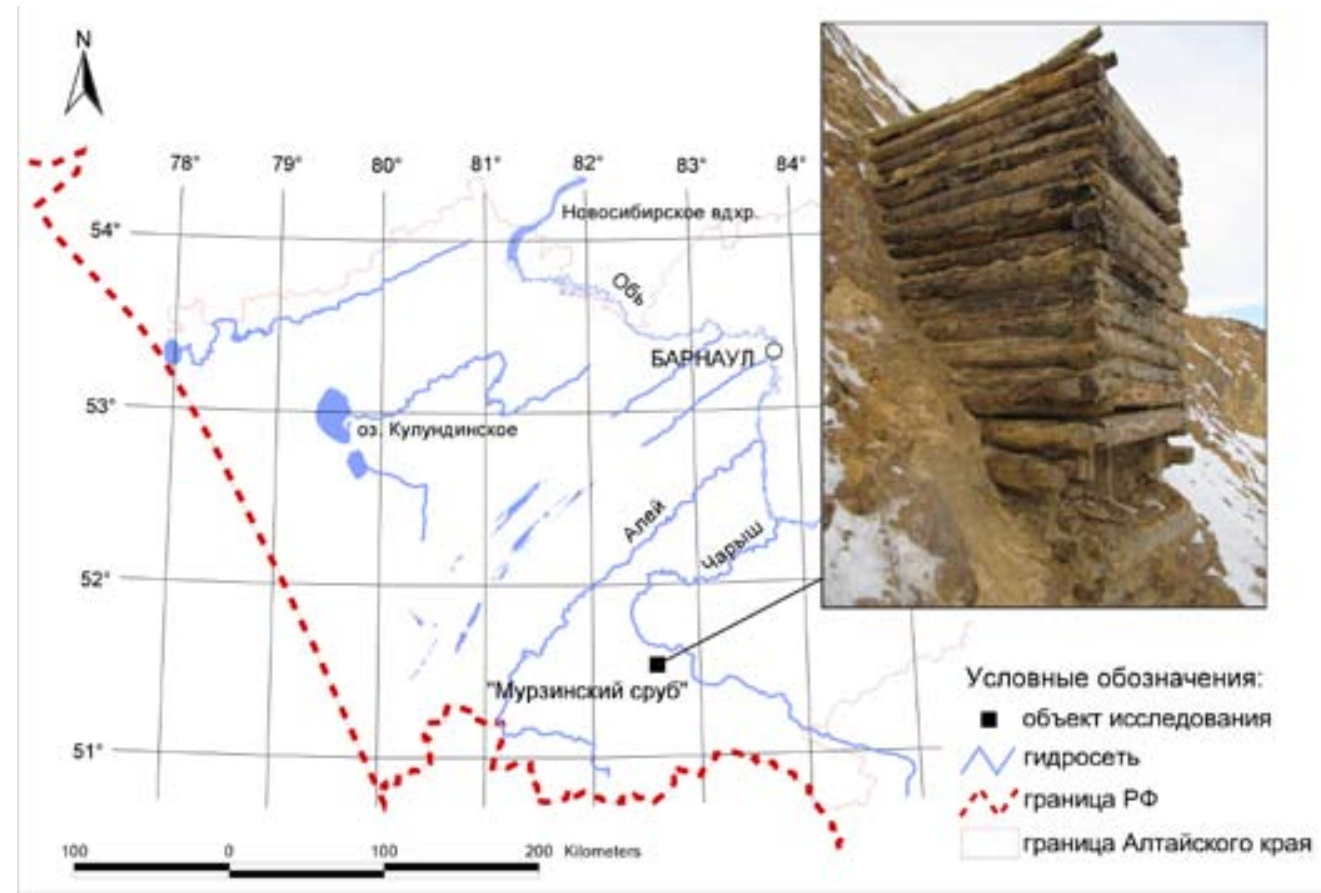

Рис. 1. Местоположение и вид обнаруженного деревянного объекта 
цов. Отбор кернов производился с той стороны бревен, на которых имелся обзол (закругленная камбиальная поверхность, открывающаяся после удаления коры), что свидетельствует о наличии подкорового кольца. Древесина ископаемого сооружения имеет достаточно хорошую сохранность, несмотря на локальные проявления процессов разрушения (гниения) верхнего слоя (рис. 1, 2).

Дальнейшая подготовка и обработка образцов к исследованию выполнялась согласно общепринятой методике (Шиятов и др., 2000; Rinn, 1996).

\section{Результаты и обсуждение}

В ходе дендрохронологических работ необходимо учитывать породу используемых для анализа деревьев, что связано с видовыми отличиями реакции деревьев на факторы окружающей среды (прежде всего климатических). Для этого был выполнен анатомический анализ древесины полученных образцов. Анализ поперечных, радиальных и тангенциальных срезов древесины позволил сделать вывод о том, что для сооружения исследуемого объекта использовалась лиственница (Larix sibirica Ledeb.). Это было предпочтительно по двум причинам: технологической (древесина данной породы деревьев долговечна и более стойкая к действию разрушающих факторов) и экономической (близкое расположение лиственничников в бассейне Среднего Чарыша, около 30 км от места строительства шахты).

В строительстве использовали стволы, содержащие 35-102 годичных кольца, достигшие в диаметре примерно 20 см. В качестве основного показателя, характеризующего изучаемые образцы, была выбрана ширина годичных колец. Средняя ширина годичных колец составила у большинства изученных образцов около 1 мм. Однако у деревьев с высокой энергией роста эта величина достигала

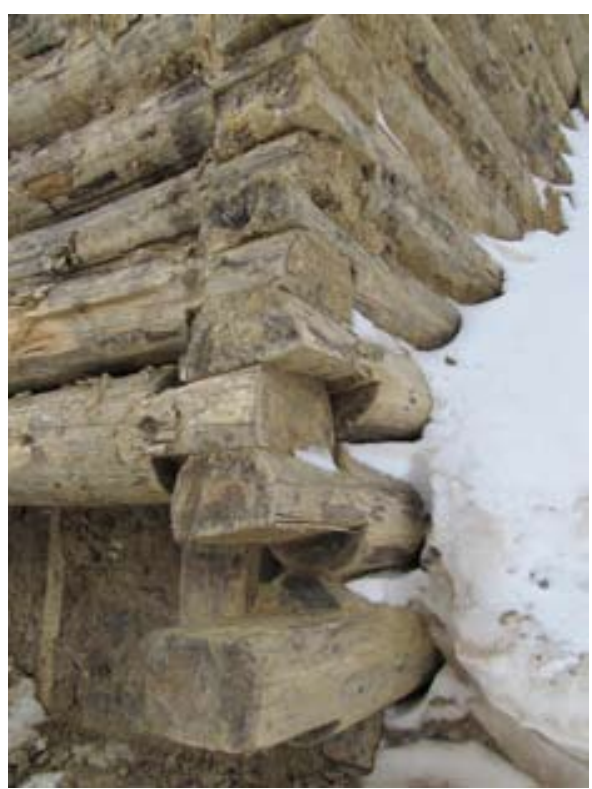

Рис. 2. Угловой венец «Мурзинского сруба»

2,5-3 мм. На основании анализа структуры последних годичных колец можно сделать вывод о том, что деревья заготавливались в течение всех сезонов года (табл.).

У многих полученных хронологий выражена возрастная кривая роста - уменьшение ширины годичных колец с увеличением возраста дерева. Возрастные тенденции наилучшим образом описывает негативная экспонента (Ваганов и др., 2000; Шишов и др., 2002; Fritts et al., 1963; Cook et al., 1995), которая была взята за основу для расчета константы минимального прироста для территории Алтае-Саянского региона (Ойдупаа, 2007). Установлено, что данная величина имеет тесную корреляционную связь со значениями среднегодовой и летней температур и, следовательно, с широтой/высотой местопроизрастания. Эта формула позволила определить, что предположительно заготовка деревьев для сооружения сруба шахты происходила на высоте 600-800 м над уровнем моря (для данного района выделяется лиственничный пояс именно на высоте 600-900 м). 
Характеристика индивидуальных хронологий «Мурзинка»

\begin{tabular}{|c|c|c|c|c|}
\hline $\begin{array}{c}\text { Индивидуальная } \\
\text { хронология }\end{array}$ & $\begin{array}{c}\text { Средняя ширина } \\
\text { годичных колец, } \\
\text { мм }\end{array}$ & $\begin{array}{c}\text { Число годичных } \\
\text { колец }\end{array}$ & $\begin{array}{c}\text { Относительное } \\
\text { датирование серий }\end{array}$ & Сезон заготовки \\
\hline MUR1 & 0,98 & 85 & $18-102$ & лето \\
\hline MUR2 & 2,97 & 35 & $68-102$ & лето \\
\hline MUR3 & 1,15 & 51 & $51-101$ & лето \\
\hline MUR4 & 2,43 & 37 & $66-102$ & лето \\
\hline MUR6 & 1,01 & 86 & $17-102$ & осень-зима \\
\hline MUR7 & 1,05 & 102 & $1-102$ & зима \\
\hline MUR8 & 1,59 & 53 & $50-102$ & лето \\
\hline MUR9 & 1,18 & 74 & $29-102$ & лето-осень \\
\hline MUR10 & 1,03 & 72 & $31-102$ & лето \\
\hline MUR11 & 1,46 & 73 & $30-102$ & зима \\
\hline MUR12 & 1,14 & 92 & $9-100$ & лето \\
\hline MUR13 & 1,07 & 89 & $14-102$ & лето \\
\hline MUR14 & 1,23 & 70 & $31-100$ & зима \\
\hline MUR15 & 2,58 & 38 & $65-102$ & осень \\
\hline MUR16 & 1,17 & 92 & $11-102$ & лето \\
\hline MUR17 & 1,02 & 59 & $44-102$ & осень \\
\hline MUR18 & 1,16 & 55 & $47-101$ & лето \\
\hline MUR19 & 1,91 & 48 & $53-100$ & лето \\
\hline MUR20 & 1,41 & 75 & $27-101$ & зима \\
\hline
\end{tabular}

Процедуре установления абсолютного возраста изучаемого сооружения предшествовало относительное датирование полученных образцов. Оно было выполнено двумя способами: по скелетным графикам и в программе COFECHA (Grissino-Mayer, 2001). В ходе датирования не было выявлено ложных и выпадающих колец, это свидетельствует о том, что использованные в строительстве деревья произрастали в сравнительно благоприятных условиях. Коэффициент чувствительности хронологий «Мурзинка» равен 0,27.

На основе высокой межсериальной корреляции, которую обнаружили 18 стандартизированных индивидуальных хронологий (коэффициент корреляции 0,43), была построена обобщенная хронология «Мурзинка» (рис. 3). Стандартизация проводилась в про- грамме ARSTAN (Holmes, 1999), в качестве аппроксимирующих кривых были выбраны линейная функция и негативная экспонента.

Для абсолютного датирования 18 индивидуальных и одной обобщенной хронологии были использованы удаленные дендрошкалы «Джело» (Центральный Алтай, склон южной экспозиции, засушливые условия) (Мыглани др., 2009) и «Коргон» (Северо-Западный Алтай, Абрамовский белок, верхняя граница леса). Хронологии «Джело» и «Коргон» показали высокую согласованность прироста (коэффициент корреляции между ними 0,53).

Датирование плавающей хронологии «Мурзинка» с древесно-кольцевыми шкалами, привязанными во времени, производили в программе COFECHА. Выбирали годы (последнего годичного кольца), которые имели 

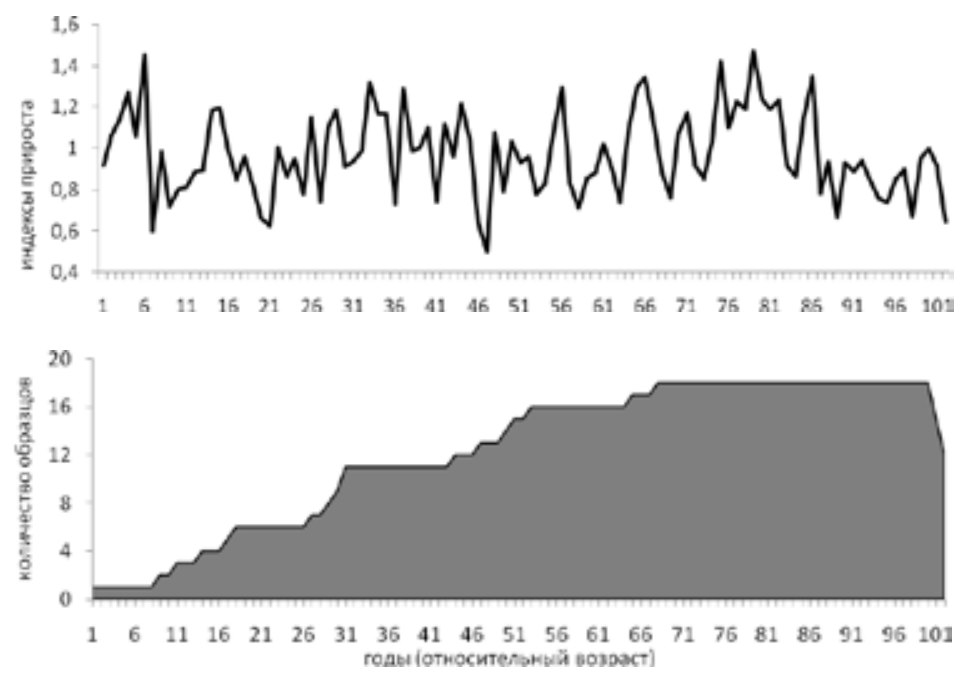

Рис. 3. Характеристика обобщенной хронологии «Мурзинка»

наиболее частую встречаемость и высокую корреляционную связь анализируемых временных отрезков. На первом этапе датирования с помощью удаленных хронологий были установлены следующие даты: 1779, 1789 и 1913 гг. Однако имеющиеся ряды «Джело» и «Коргон» отражают условия верхней границы леса, которые отличаются по условиям местообитания от нижней границы, где, вероятнее всего, заготовлены деревья для сооружения изучаемого объекта.

Этим обусловлено проведение второго этапа работ, в ходе которых был выполнен дендрохронологический анализ обнаруженного деревянного сооружения на основе созданной близкой древесно-кольцевой хронологии по лиственнице. Анализ литературных данных и космических снимков позволил установить место наиболее вероятного отбора необходимых образцов - бассейн р. Иня. В настоящее время это ближайший район к с. Акимовка, где произрастают 200-300-летние лиственницы. В ходе полевых работ были отобраны буровые образцы (керны) с лиственниц в 4 км южнее с. Генералка Краснощековского района (59 км от с. Акимовка).
Характеристика полученных индивидуальных дендрорядов «Генералка» представлена на рис. 4. Средний возраст древесно-кольцевых серий составил 289 лет, максимальный - 397 лет. Таким образом, полученные хронологии охватывают весь период горно-рудной деятельности на Алтае.

Датирование на основе хронологий «Генералка» также не дали однозначного результата: были выделены 1772, 1923 и 1945 гг. (рис. 5). Из 19 хронологий 9 указывают на 1923 и 1945 гг., 8 хронологий - на 1772 г.; эта незначительная разница может быть объяснена тем, что в XVIII в. наполняемость образцами мастер-хронологии «Генералка» меньше по сравнению с XIX и XX вв. (рис. 4). Это также может быть причиной некоторого уменьшения средних коэффициентов корреляции для 1772 г. по сравнению с 1923 и 1945 гг.

На этапе верификации полученных результатов проведен статистический контроль полученных дат. Годы, которые были выделены программой СОFЕСНА, проверены методом скользящей корреляции обобщенной хронологии «Мурзинка» с мастер-хронологией 

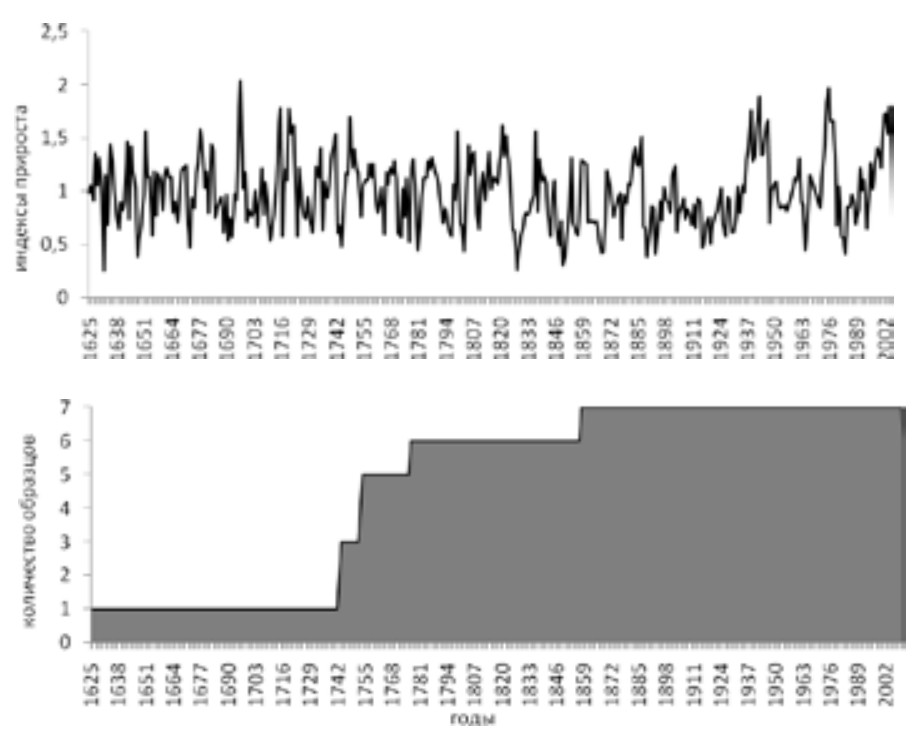

Рис. 4. Характеристика обобщенной хронологии «Генералка»

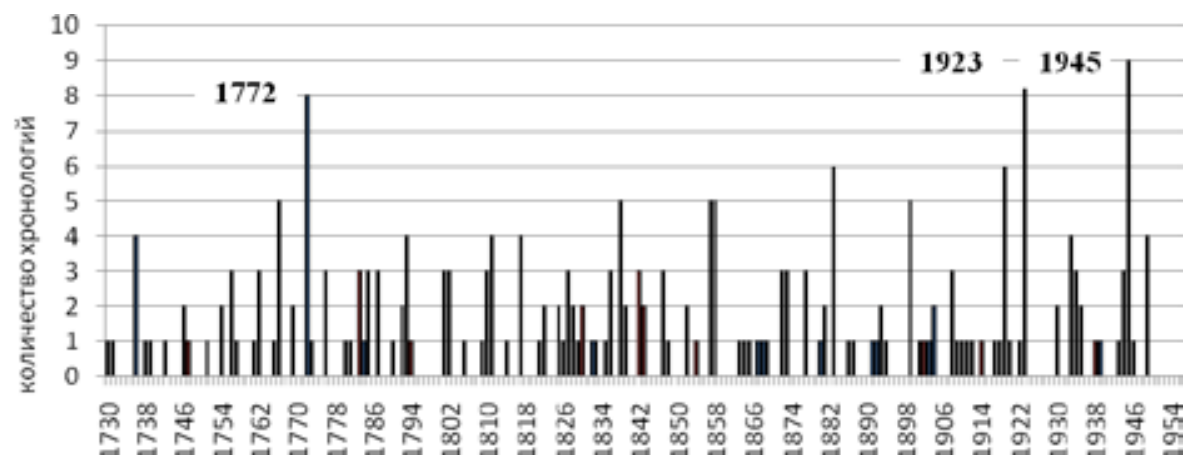

Рис. 5. Число индивидуальных стандартизированных хронологий «Мурзинка», датируемых конкретной календарной датой на основе дендрошкалы «Генералка»

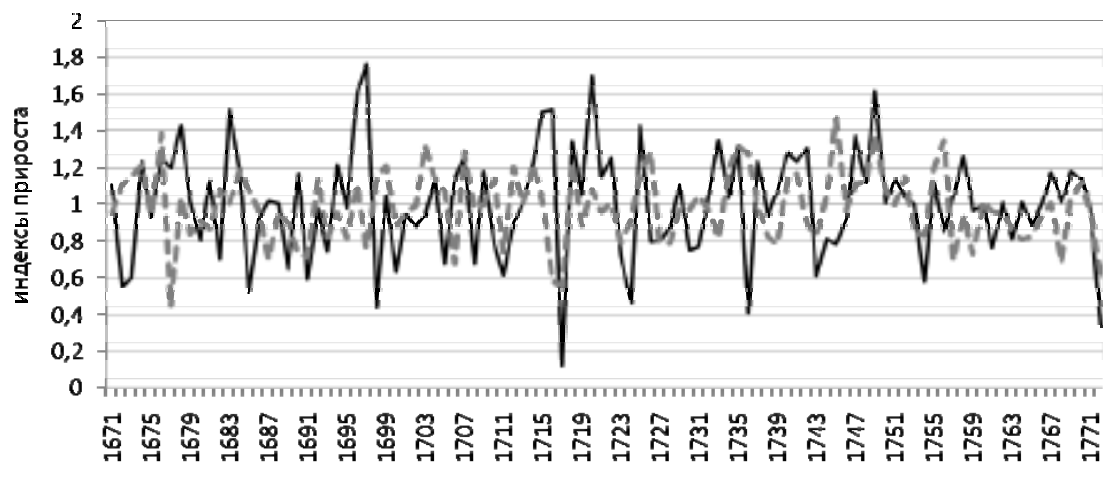

Рис. 6. Сравнение хронологий «Генералка» и «Мурзинка», датированной 1772 г. 
«Генералка». Скользящий корреляционный анализ обобщенной хронологии «Мурзинка» с мастер-хронологией «Генералка» показал наилучший результат для 1772 г.: коэффициент корреляции (r) =0,18 (рис. 6). В качестве сравнения - для 1923 г. r =0,09; для 1945 г. $\mathrm{r}=0,13$.

Обобщая результаты выполненного датирования древесины сруба, обнаруженного на Мурзинском-I месторождении, можно выделить три предполагаемых даты заготовки древесины: 1772, 1923 и 1945 гг. В ходе верификации установлено, что наиболее вероятной датой является 1772 г.

\section{Заключение}

Итогом выполненной работы явилось датирование типичного для Рудного Алтая объекта горно-рудного производства XVIII в. Подтверждением данного вывода явились результаты археологических исследований исторического памятника. В связи с развитием туристско-рекреационного кластера на Алтае исторические памятники горнорудного производства представляют собой ценный ресурс для обозначенной отрасли экономики. Датирование исследованного объекта способствовало его музеефикации, для чего были инвестированы около 10 млн руб. Несомненно, что процесс перевода подобных артефактов в музейные экспонаты будет продолжаться. Это требует дальнейшего совершенствования информационной базы для дендрохронологического датирования объектов в данном регионе: создание древесно-кольцевых хронологий по различным породам деревьев и местообитаниям, увеличение их числа и длины. Подобная работа будет способствовать формированию мировой сети дендрополигонов.

Работа выполнена при финансовой поддержке Российского фонда фундаментальных исследований (грант 11-06-00242-а).

\section{Список литературы}

Ваганов Е.А., Бриффа К.А., Наурзбаев М.М., Швейнгрубер Ф.Г., Шиятов С.Г., Шишов В.В. (2000) Длительные климатические изменения в арктической области северной области полушария. Доклады АН 375 (1): 103-106.

Мыглан В.С., Овчинников Д.В., Ваганов Е.А., Быков Н.И., Герасимова О.В., Сидорова О.В., Силкин П.П. (2009) Построение 1772-летней древесно-кольцевой хронологии для территории республики Алтай. Известия РАН. Серия географическая 6: 70-77.

Ойдупаа О.Ч. (2007) Дендроклиматический анализ радиального прироста лиственницы в Республике Тыва: автореф. ... канд. биол. наук, 03.00.16. Красноярск, 21 с.

Черных Н.Б. (1996) Дендрохронология и археология. М.: №x, 216 с.

Шишов В.В., Ваганов Е.А., Хьюс М.К., Корец М.А. (2002) Пространственная изменчивость радиального прироста деревьев на территории Сибири в последнем столетии. Доклады АН 387 (5): 690-693.

Шиятов С.Г., Ваганов Е.А., Кирдянов А.В., Круглов В.Б., Мазепа В.С., Наурзбаев М.М., Хантемиров Р.М. (2000) Методы дендрохронологии. Ч. І. Красноярск: Изд. КрасГУ, 80 с.

Cook E.R., Briffa K.R., Meko D.M., Graybill D.A., Funkhouser G. (1995) The 'segment length curse' in long tree-ring chronology development for palaeoclimatic studies. The Holocene 5(2): $229-237$. 
Fritts H.C., Mosimann J.E., Bottorff C.P. (1963) A Revised Computer Program for Standardizing Tree-Ring Series. Tree-Ring Bulletin 29 (1-2): 15-20.

Grissino-Mayer H.D. (2001) Evaluating Crossdating Accuracy: A Manual and Tutorial for the Computer Program Cofecha. Tree-Ring Research 57 (2): 205-211.

Holmes R.L. (1999) Dendrochronology Program Library (DPL) Users Manual. LTRR University of Arizona, Tuscon.

Rinn F. (1996) TSAP-Reference Manual. Heidelberg, 263 p.

\title{
The Dendrochronological Research \\ of Mining Works Historical Object on Altai
}

\author{
Nikolai I. Bykov and Natalia V. Malysheva \\ Altai State University, \\ 61 Lenina, Barnaul, 656049 Russia
}

\begin{abstract}
The article presents the results of dendrochronological research of mining works historical object which was found in foothills of Altai in 2010-2011 during overburden operations in Murzinsky quarry. The uncovered construction is a trunk shore of vertical mine working existing here earlier. Results of the complex analysis revealed that larches of age 35-102 years which grew at heights 600-800 meters were used for the object building. The most probable year based on two-stage dating following by the results' verification of wood harvesting for the studied construction is the 1772. The final observations made it possible to specify peculiarities and the development chronology of the following territory.
\end{abstract}

Keywords: dendrochronology, dendroarchaeology, mining production. 